\title{
Cartographic Support of Local Environmental Monitoring of Licensed Areas of Oil Production Enterprises of the Khanty-Mansi Autonomous Okrug - Yugra
}

\author{
Evgeniya Kozelkova*, Boris Seredovskikh, Alina Vasikova, and Vladimir Isypov \\ Nizhnevartovsk State University, Nizhnevartovsk, Russia
}

\begin{abstract}
The work includes environmental monitoring of the license areas of oil production enterprises of the Khanty-Mansi Autonomous Okrug. The main geological and ecological problems on the territory of the study object (Bakhilov license area) were identified. The spatial information sources of the use of GIS technologies for the creation of cartographic material were analyzed. The spatial information sources of the use of GIS technologies for the creation of cartographic material were analyzed. Methods of drawing up a project of an auxiliary coordinate network of locations of checkpoints and sampling and drawing up maps in the QGIS program were considered. Based on the standard GIS functionality, a cartographic model of the project plan for local environmental monitoring of license areas of the Bakhilov group of fields has been developed. Thanks to the series of maps created by the cartographic method, it is possible to monitor the anthropogenic load on the landscapes of the territory, the dynamics of the areas of anthropogenic changes, the degree of degradation of natural complexes.
\end{abstract}

\section{Introduction}

According to regulatory documents, oil-producing enterprises are obliged to conduct local environmental monitoring (LEM) during the period of oil and gas fields development as an integrated system of regular observations, collection of information, assessment, and forecasting of spatial and temporal changes in the state of environmental components under the influence of natural and anthropogenic factors within the boundaries of the licensed subsoil area.

Local environmental monitoring in the Khanty-Mansi Autonomous Okrug - Yugra has a legal background based on the Regulation on the organization of local environmental monitoring within the boundaries of licensed areas for the right to use subsoil for oil and gas production.

The relevance of the work lies in the fact that Nizhnevartovsky District, as one of the main oil and gas producing regions of the Khanty-Mansi Autonomous Okrug - Yugra, must have more stringent requirements on the state of environmental components, due to the

\footnotetext{
* Corresponding author: arctic_arrow@ mail.ru
} 
danger of oil pollution. Moreover, a necessary attribute of LEM is the mapping of the obtained material during environmental control and monitoring.

The work aims to develop a cartographic model of the project plan for local environmental monitoring of license areas using GIS technologies.

The object of research is local environmental monitoring of license areas for the right to use subsoil for the purpose of oil and gas production in the Bakhilov group of fields.

The subject of the research is the mapping of objects of local environmental monitoring of license areas using GIS technologies. The data can be used to solve geographic and environmental problems [1].

\section{Characteristics of the Research Area}

\subsection{Physical and geographical description of the research object}

The Bakhilov group of fields includes the Bakhilov, Severo-Khokhryakovsk, and VerkhneKolik-Yegansk fields, which are located in the central part of the West Siberian Plain (Fig. $1)$.

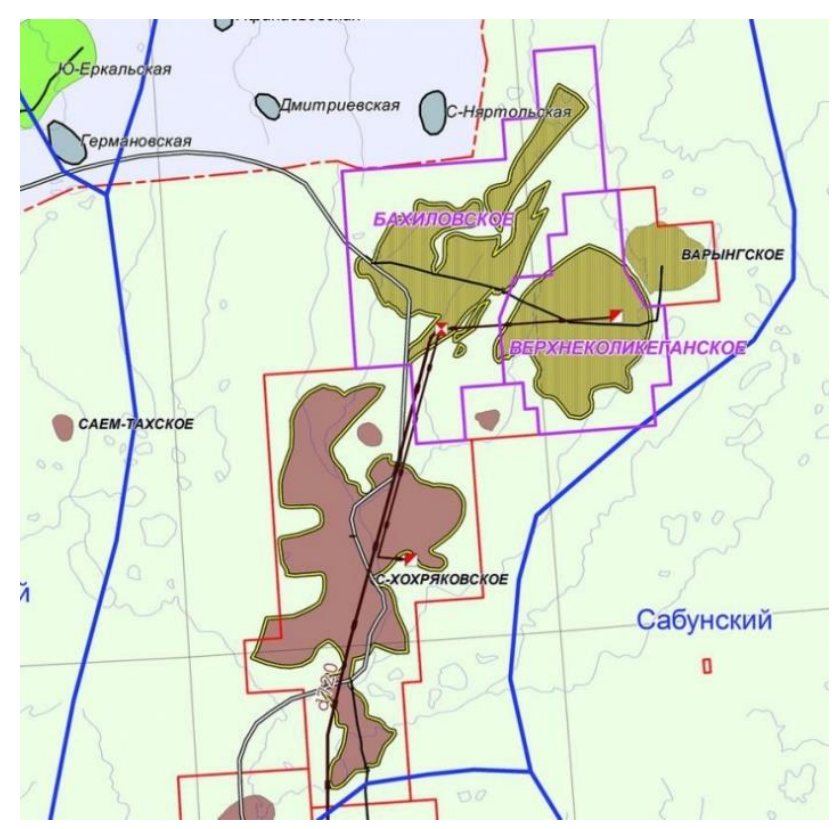

Fig. 1. General map of the Bakhilov group of fields.

The considered territory belongs to the Nizhnevartovsky District of the Khanty-Mansi Autonomous Okrug - Yugra.

The Bakhilov field is located within the Siberian Uvaly of the West Siberian Plain and belongs to the area of the quaternary aqua glacial plain. The field territory is included in the area of accumulative flat plains development. In terms of geomorphological zoning, the territory belongs to the accumulative denudation plain.

According to the scheme of physical and geographical zoning of the Tyumen Region by N.A. Gvozdetsky, area of work is located in the Ob-Irtysh province of the forest plain latitudinal-zonal region and, according to SNiP 23-01-99, belongs to the I climatic region [2].

The surface is characterized by a flat, gently undulating relief in varying degrees of complicated erosional forms of relief and widespread development of bog and bog-lacustrine 
complexes in the interfluves. Geographically, the research area is located in the Okhogrigol river basin. The territory is located in the forest zone within the subzones of the northern and middle taiga, characterized by a wide variety of soil and vegetation cover, the largest part of the territory is covered with typical bog vegetation [3].

At the field stage of research, a natural survey of land plots requested under the project "Bakhilov field infrastructure development. Cluster site No. 148".

\subsection{Characteristics of the technogenic load of the licensed area}

The research area is experiencing a great anthropogenic impact. During the field and laboratory studies, an excess of many polluting indicators was found, such as chlorides, oil products, etc.

The main technological processes that cause environmental pollution during the operation of the field are:

- construction of oil wells;

- collection, primary treatment and transportation of oil and water;

- transportation of oil through oil pipelines;

- production and social infrastructure.

Currently, there are 95 operating producing wells, and 55 injection wells. Waterflooding is carried out in a closed block system

There are production and auxiliary production zones on the territory of the Bakhilov field.

The production zone includes: well pads; exploration well P-301; support base for managing the operation of oil production facilities; flare system; booster pumping station with a preliminary water discharge unit, modular integrated pumping station.

The auxiliary production zone includes the support base of the production field, shift camp, water treatment facilities, point of loading and discharging of oil, borrow pit, infield pipelines, roads (line communication facilities).

Even small pollution, without the oil film cover, leads to a slowdown in the growth and development of plants, phytotoxic microflora develops, and soil animals are inhibited. Oil products are washed out by rains or melting snow from the soil into groundwater and surface waters. That, in turn, should influence its results according to the principles of environmental zoning [4].

When performing environmental, or any other functional zoning of the territory in the dimension of one administrative region and larger, such contaminated land plots from the existing register, as well as places of local accidents (incidents) on pipelines, can be placed on the zoning map only in the form of point objects [5].

\section{Research methodology}

When conducting research, it is important to choose the right methods for geo-ecological monitoring of the geological environment state, these include Remote methods (cartographic method, method of photogrammetry and remote sensing of territories; Field methods (manual/morphometric method, field method using satellite equipment) $[6,7]$.

A number of methods have been applied in the research work: Descriptive; Analytical; Ecological and Geographical; Statistical and Mathematical; Cartographic.

The methodology for drawing up a draft of an auxiliary coordinate network of checkpoints and sampling points includes the following items [8]:

- Development of a project for an auxiliary coordinate network of checkpoints locations and sampling on the territory of the license area.

- Clarification of the location of sampling points using the GPS navigator GARMIN MONTANA 
- Recording in the register of coordinates of the point location and recalculation of geographical coordinates into the WGS-84 system

The methodology for developing a map for a licensed area includes:

- Creation of a basic GIS project containing the topographic basis of the research area

- Drawing up a landscape and ecological map with the attachment of a working set and a legend

- Drawing up layers with information about the points of the observation network for environmental monitoring and objects of man-made load.

Practice has shown that in order to speed up the approval procedure for reports, it is necessary to follow the following recommendations when preparing cartographic material:

- The map of the licensed area must be drawn up on a vector topographic basis, including information on the main components: relief (indicate the value of the heights assigned to the contours in the attributes; vegetation cover and soils (indicate the types of vegetation and soils in the attributes); hydrography (indicate the type and name of the water body in the attributes).

- Work sets and a legend should be attached to the landscape-ecological map. In addition, when using additional fonts (symbols) that are not part of the standard MapInfo (QGIS) set, files containing these additional fonts (symbols) must be provided

- Information about the points of the observation network of environmental monitoring should be drawn up as a separate layer. Indicate the name (number) of the point of the observation network of environmental monitoring and the investigated component of the natural environment (atmospheric air, surface water, bottom sediments, soil) in the attributes. - Industrial facilities shown on the map must fully comply with the facilities accounted for in the table of man-made impact provided to the authorized environmental authorities.

The basic set should contain two sets of layers with industrial objects: "basic" set reflecting the state for the year of the start of the LEM project; a "new" set with objects introduced during the operation of this project. Objects of layers in this set must have an additional attribute "Year of commissioning".

- Each set must contain the following set of layers (required attributes): "pipelines" category (trunk, interfield, infield), type (oil pipelines, gas pipelines, water pipelines); "Wells": name (number), type (exploration/prospecting); "Well pads": name (number) of the well pad; "Other industrial sites": name (number), type of facility (booster pumping station, oil treatment plant, quarry, waste landfill, treatment facilities, etc.); "Sludge pits": the name of the pit, stage and period of reclamation; "Roads": category (paved roads, unpaved roads, field roads, winter roads); "Flare": name (number), operating mode (constant/periodic); other large stationary sources of air emissions; "Oil-contaminated lands": date (year) of the spill, the area of the spill (ha).

- Onsite facilities, such as booster pump station, cluster pump station, central production facility, well pads, well cleanout complex, biological waste, solid domestic waste, production service, etc., must be displayed as a single graphic object without splitting one area object into parts.

- Indicate the name of the owner for objects belonging to other enterprises.

\section{Research Results}

Field trips to the investigated territory of the Bakhilov group of fields were undertaken in order to clarify the location of sampling points and recording coordinates in the register with recalculation in the WGS-84 geographic coordinate system.

The resulting cartographic material (route tracks, coordinates of sampling sites) was further processed in the specialized program GARMIN BASE CAMP. 
Based on the standard functionality of geoinformation systems, a cartographic model of the project plan for local environmental monitoring of license areas of the Bakhilov group of fields has been developed. Using a series of maps created by the cartographic method (General map of the Bakhilov licensed area with man-made load (Fig. 2); sampling map; map of the ecological background of the Bakhilov license area; landscape and geoecological map of the Bakhilov license area), it is possible to monitor the anthropogenic load on the landscapes of the territory, dynamics of areas of anthropogenic changes, the degree of degradation of natural complexes.

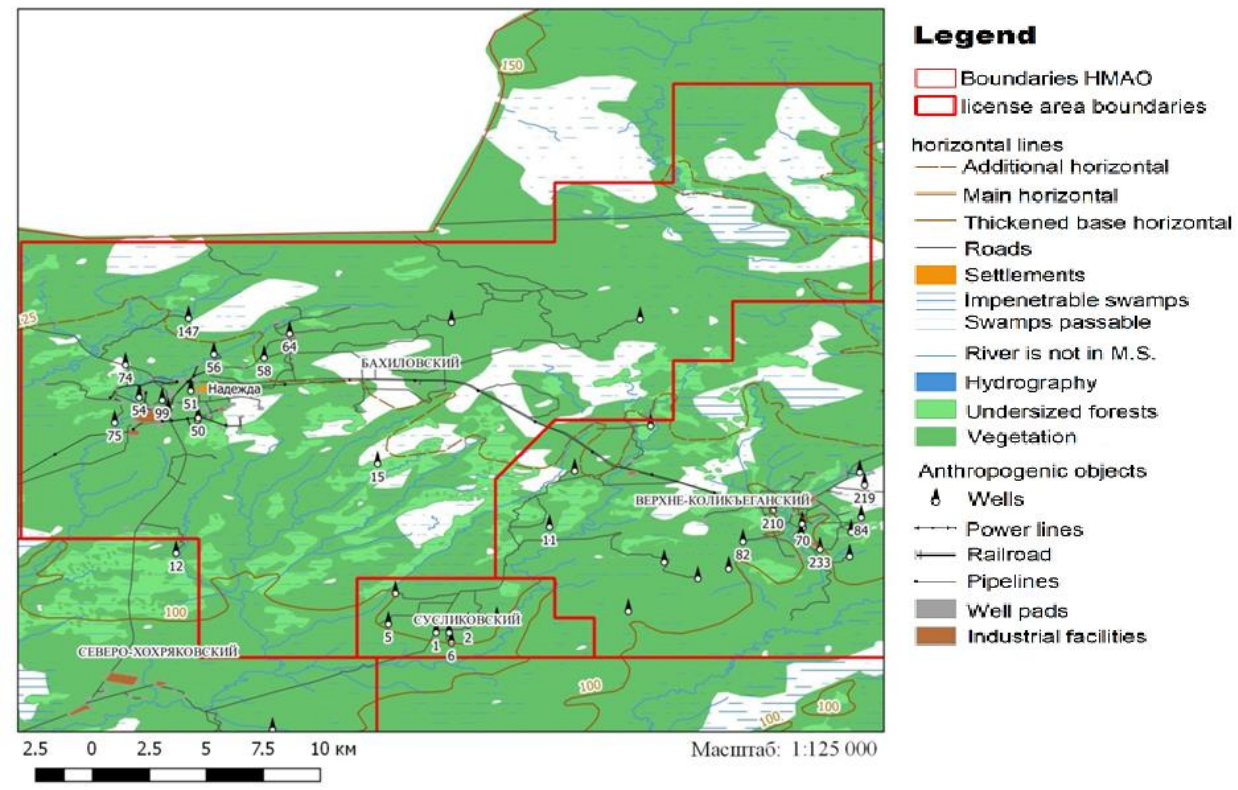

Fig. 2. General map of the Bakhilov license area with man-made impact.

Of course, in environmental zoning, it is necessary to take into account all available known data of anthropogenic impact on the environment. Mapping a large number of small objects contained in such a register presents some difficulty due to the amount of work, and it's preferable to use them in the absence of other data on environmental pollution [9]. At the same time, depending on the number of objects of pollution, it is necessary to resolve the issue of the dimension (units of measurement) of indicators. It will be permissible to accept them when mapping as separate zones or continuous pollution of the territory at a certain level.

\section{Discussion of Results}

At the first stage of creating a cartographic model of the project plan for local environmental monitoring, a general map of the territory of the Bakhilov license area was developed with information about the hydrological network, man-made impact, as well as information about large man-made objects and linear communications of neighboring territories. The following geotechnical systems are reflected on the map: operating trunk, interfield, infield pipelines, exploration, and prospecting wells; well pads; other industrial facilities (booster pump stations, oil treatment facilities, etc.); highways; power lines.

Then, a general map was plotted with the location of sampling points for the components of the natural environment. 
To create a cartographic model of the project plan for local environmental monitoring, several trips to the Bakhilov license area were made to determine the sampling points.

Four sampling point tables have been created:

1)Air;

2)Soils;

3)Ground waters;

4)Surface waters.

The locations of the sampling points were specified using a GPS navigator and recalculated in the WGS-84 UTM Zone $44 \mathrm{~N}$ geographic coordinate system, necessary to create a project monitoring plan in this projection.

The next step was the creation of a landscape map of the Bakhilov license area with an indication of man-made objects and the location of all sampling points. The map of the landscapes of the Khanty-Mansi Autonomous Okrug - Yugra (Fig. 3) was taken as the basis (substrate) of this map.
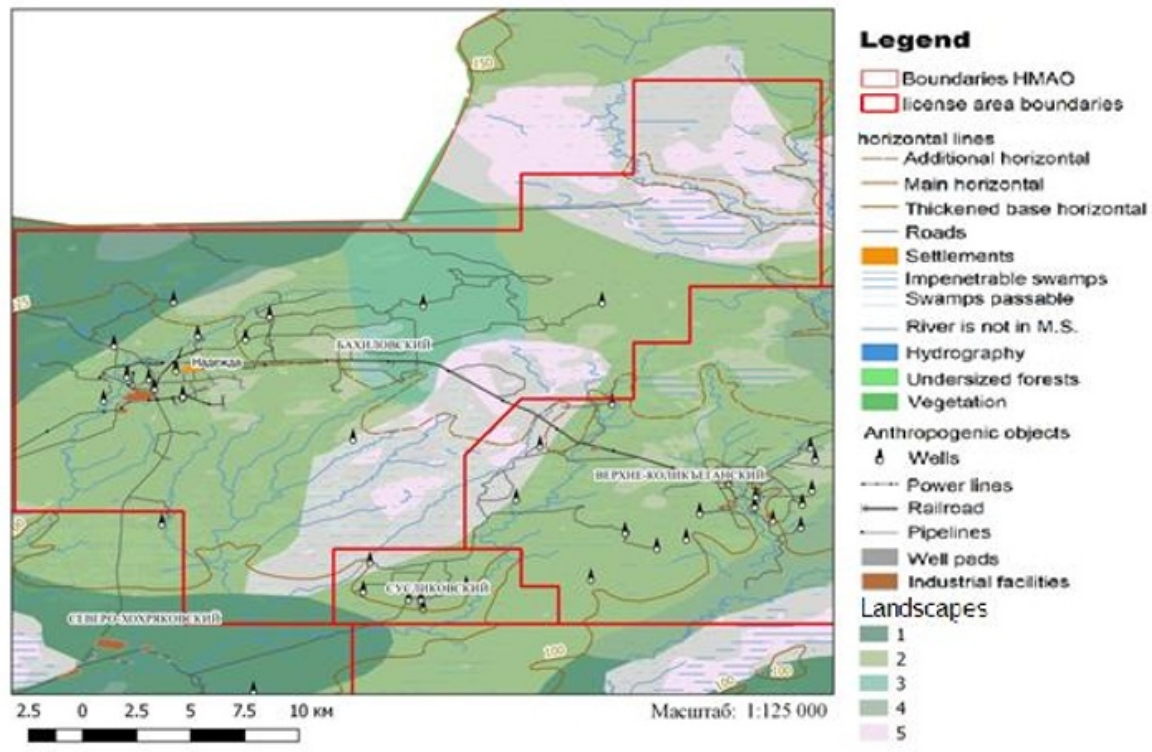

Fig. 3. Comprehensive landscape and geoecological map of the Bakhilov license area.

Map key (landscapes):

1 - flat, slightly sloping elevated drained plains with spruce-cedar-larch lichen-mossshrub forests on podzolic gley soil and podzolized gley cryogenic soils with sphagnum bogs at times;

2 - flat relatively drained plains with pine-cedar forests on podzolic gley soils and sparse forests on peat-podzolic-gley soils with areas of ridge-hollow flat-hilly bogs

3 - flat, low-inclined plains with peat valley-like depressions at times, with dark coniferous-birch-pine forests on gley light soils

4 - flat, low-inclined slopes of interfluves, dissected by watercourses and valley-like depressions with light coniferous shrub-moss forests on gley podzols and illuvial-ferruginous podzols on ridges in a complex with ridge-hollow bogs on oligotrophic boggy soil

5 - ridge-lake-hollow bogs with pine shrub-sphagnum oppressed forests (riams) along ridges and moss-lichen hollows

And the final stage in the development of the project plan for local environmental monitoring of the Bakhilov license area was the creation of a geoecological map with the 
allocation of the environmental background, on which territories with a natural and disturbing environmental background are shown using coloring (Fig. 4).

\section{Environmental background}

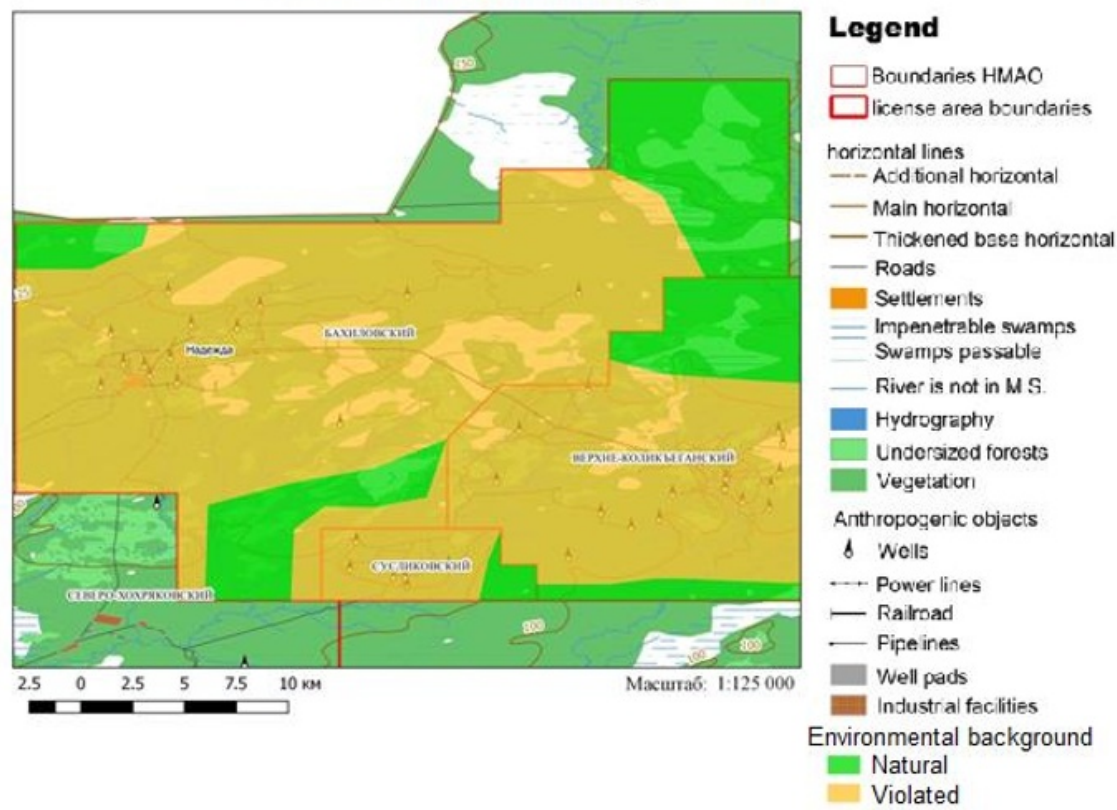

Fig. 4. Map of the ecological background of the Bakhilov license area

\section{Conclusions}

The research gives the physical and geographical characteristics of the research area, which includes consideration of the geographical position, geological and geomorphological characteristics, climate and hydrological features, as well as soil and vegetation. The main geoecological problems on the territory of the research object (Bakhilov license area) have been identified.

The spatial information sources of the use of GIS technologies for the creation of cartographic material were analyzed. Methods of drawing up a project of an auxiliary coordinate network of locations of checkpoints and sampling and drawing up maps in the QGIS program were considered.

The results of the work can be used to analyze and study the geoecological situation and environmental monitoring [10] of the Nizhnevartovsky District territory by students of Nizhnevartovsk State University during practical classes in environmental disciplines, as well as for the development of environmental protection measures by the oil-producing enterprises of the okrug.

\section{References}

1. A.A. Safonenko, E.N., Kozelkova, G.N. Grebenyuk, Izvestia of the Samara Scientific Center of the Russian Academy of Sciences 17(6), 140 (2015)

2. D.B. Seredovskikh, B.A. Seredovskikh, S.N. Sokolov, Current state of the problem of reclamation of oil sludge pits in the Khanty-Mansiysk Autonomous Okrug-Yugra. XX All-Russian student scientific-practical conference of Nizhnevartovsk State University: 
collection of articles, otv. ed. A.V. Korichko. Part 1. Biology. Ecology. Geography. Cartography. Life safety. Power engineering. Electrical Engineering, 203 (Nizhnevartovsk: Publishing house of Nizhnevart State University, 2018)

3. S.E. Korkin, V.A. Isypov, E.A. Korkina, Landscape-hydrological organization of the territory of the middle $\mathrm{Ob}$ region with an analysis of erosion processes. Geographic foundations and ecological principles of the regional policy of nature management. International Scientific and Practical Conference dedicated to the memory of RAS Corresponding Member A.N. Antipova, 137 (Irkutsk: V.B. Sochava Institute of Geography, Siberian Branch of the Russian Academy of Sciences, 2019)

4. O.I. Kremlev, E.N. Kozelkova, Influence of local oil pollution of soils on the results of environmental zoning. Culture, science, education: problems and prospects: materials of the VI international scientific-practical conference, 34 (Nizhnevartovsk: Nizhnevartovsk state university, 2017)

5. V. Kuznetsova, E. Kuznetsova, A. Kushanova, E. Kozelkova, Analysis of agricultural lands in Nizhnevartovsk based on geo-information mapping. 19th International Multidisciplinary Scientific Geoconference SGEM 2019 Conference proceedings, (Publisher: STEF92 Technology Limited Liability Company, 2019)

6. S. E. Korkin, V. A. Isypov, Methods of geoecological monitoring of the state of the geological environment: on the example of the middle $\mathrm{Ob}$ region. Culture, science, education: problems and prospects: materials of the VIII All-Russian scientific-practical conference with international participation, Nizhnevartovsk: Nizhnevartovsk State University, 10 (2021). DOI 10.36906/KSP-2020/02.

7. S. E. Korkin, V. A. Isypov, E. A. Korkina, Landscape-hydrologic systems and erosion processes across the middle $\mathrm{Ob}$ region. IOP Conference Series: Earth and Environmental Science: International Scientific and Practical Conference in Commemoration of Corr. Mem., RAS, A.N. Antipov "Geographical Foundations and Ecological Principles of the Regional Policy of Nature Management", P. 012047 (Irkutsk: Institute of Physics Publishing, 2019). DOI 10.1088/1755-1315/381/1/012047.

8. D.B. Seredovskikh, R.I. Smakova, Regional requirements for cartographic support of local environmental monitoring of license areas of oil-producing enterprises of the Khanty-Mansiysk Autonomous Okrug - Ugra. Culture, science, education: problems and prospects: VII All-Russian scientific-practical conference with international participation, otv. ed. D.A. Pogonyshev, Nizhnevartovsk: Nizhnevartovsk State University, 88 (2019)

9. E. N. Kozelkova, V. P. Kuznetsova, A. U. Kushanova, A. O. Besedina, Natural and technical sciences 6 (132), 133 (2019)

10. O.I. Kremlev, E. N. Kozelkova, Reconstruction of the natural state of disturbed ecosystems by the method of environmental zoning. In the collection: Culture, science, education: problems and prospects. V International Scientific and Practical Conference, otv. ed. A.V. Korichko, 48 (2016) 